\title{
P05.34. Well-being and wellness behaviors among family medicine residents: an exploratory descriptive study
}

\author{
A Brooks ${ }^{1 *}$, S Dodds ${ }^{1}$, M Guerrera ${ }^{2}$, P Cook ${ }^{1}$, R Benn ${ }^{3}$, P Lebensohn ${ }^{1}$ \\ From International Research Congress on Integrative Medicine and Health 2012 \\ Portland, Oregon, USA. 15-18 May 2012
}

\section{Purpose}

To present longitudinal changes on dimensions of wellbeing and wellness behaviors among residents in eight family medicine (FM) residencies.

\section{Methods}

FM residents in the 2011 graduating class $(n=56)$ were assessed at four time points, the beginning of each of the three years of residency and at graduation. Measures were self-administered online and included established measures of well-being: perceived stress, burnout (emotional exhaustion and depersonalization), emotional intelligence (empathy and perspective taking), depression, positive and negative affect, satisfaction with life, mindfulness, gratitude, and a measure of wellness behaviors (sleep, nutrition, physical activity, mind-body activities, being in nurturing relationships, being outdoors in nature, and alcohol use).

\section{Results}

Perceived stress and positive affect were stable across PGY1, PGY2, and PGY3, but decreased significantly by graduation $(\mathrm{p}=.0005 ; \mathrm{p}=.0011$, respectively). Burnout (emotional exhaustion and depersonalization) increased significantly at the start of PGY2 and remained high through graduation $(p=<0.0001)$. Emotional intelligence (empathy and perspective taking) decreased significantly from PGY2 to PGY3, but returned to PGY2 levels by graduation $(\mathrm{p}=<0.0001)$. Life satisfaction decreased in PGY2 and PGY3 but returned to PGY1 level by graduation $(\mathrm{p}=.0015)$. Depression, alcohol use, mindfulness, and gratitude remained stable throughout the residency. Two wellness behaviors showed significant increases across time, eating 5 servings of fruits and vegetables daily $(\mathrm{p}=.0005)$ and waking rested from sleep ( $\mathrm{p}=.0433)$.

\section{Conclusion}

Findings suggest that resident stress and distress persist throughout residency, but by graduation stress is reduced and positive affect, emotional intelligence, and life satisfaction return to improved levels from the baseline. Despite the rebound on these dimensions, the emotional exhaustion and depersonalization of burnout remained high at graduation. Only two wellness behaviors improved during the IMR residency, diet and sleep. These are preliminary results of a much larger study involving family medicine residents with and without a core curriculum in integrative medicine.

\section{Author details}

${ }^{1}$ University of Arizona, Tucson, USA. ${ }^{2}$ University of Connecticut, School of Medicine, Hartford, USA. ${ }^{3}$ University of Michigan Health System, Ann Arbor, USA.

Published: 12 June 2012

doi:10.1186/1472-6882-12-S1-P394

Cite this article as: Brooks et al:: P05.34. Well-being and wellness

behaviors among family medicine residents: an exploratory descriptive study. BMC Complementary and Alternative Medicine 2012 12(Suppl 1):P394.

'University of Arizona, Tucson, USA

Full list of author information is available at the end of the article

(c) 2012 Brooks et al; licensee BioMed Central Ltd. This is an Open Access article distributed under the terms of the Creative Commons Attribution License (http://creativecommons.org/licenses/by/2.0), which permits unrestricted use, distribution, and reproduction in any medium, provided the original work is properly cited. 